\title{
ESGE and ESGENA Position Statement on gastrointestinal endoscopy and COVID-19: Updated guidance for the era of vaccines and viral variants
}

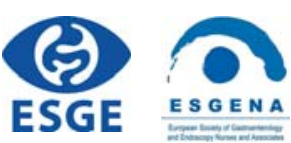

Ian M. Gralnek* ${ }^{*}$, Cesare Hassan ${ }^{*}, 2,3$, Alanna Ebigbo ${ }^{4}$, Andre Fuchs ${ }^{4}$, Ulrike Beilenhoff ${ }^{5}$, Giulio Antonelli6,7, Raf Bisschops $^{8} \odot$, Marianna Arvanitakis ${ }^{9}$, Pradeep Bhandari ${ }^{10}$, Michael Bretthauer ${ }^{11}$, Michal F. Kaminski ${ }^{12}$, Vicente Lorenzo-Zuniga $^{13}{ }^{\oplus}$, Enrique Rodriguez de Santiago ${ }^{14} \odot$, Peter D. Siersema ${ }^{15}$, Tony C. Tham ${ }^{16}$, Konstantinos Triantafyllou ${ }^{17} \odot$, Alberto Tringali ${ }^{18}$, Andrei Voiosu19,20 $\odot$, George Webster ${ }^{21}$, Marjon de Pater ${ }^{22}$, Björn Fehrke ${ }^{23}$, Mario Gazic ${ }^{24}$, Tatjana Gjergek ${ }^{25}$, Siiri Maasen ${ }^{26}$, Wendy Waagenes ${ }^{27}$, Mario Dinis-Ribeiro ${ }^{28}$, Helmut Messmann ${ }^{4}$

Institutions

1 Ellen and Pinchas Mamber Institute of Gastroenterology and Hepatology, Emek Medical Center, Afula, Israel and Rappaport Faculty of Medicine Technion Israel Institute of Technology, Haifa, Israel

2 Endoscopy Unit, IRCCS Humanitas Clinical and Research Center, Rozzano, Milan, Italy

3 Department of Biomedical Sciences, Humanitas University, Pieve Emanuele, Milan, Italy

4 III Medizinische Klinik Universitätsklinikum Augsburg, Augsburg, Germany

5 European Society of Gastroenterology Nurses and Associates (ESGENA)

6 Department of Anatomical, Histological, Forensic Medicine and Orthopedics Sciences, Sapienza University of Rome, Rome, Italy

7 Gastroenterology and Digestive Endoscopy Unit, Ospedale dei Castelli di Ariccia, Rome, Italy

8 Department of Gastroenterology and Hepatology, Catholic University of Leuven (KUL), TARGID, University Hospitals Leuven, Leuven, Belgium

9 Erasme University Hospital, Brussels, Belgium

10 Gastroenterology, Portsmouth Hospital NHS Trust, Portsmouth, United Kingdom

11 Clinical Effectiveness Research Group, University of Oslo, and Department of Transplantation Medicine, Oslo University Hospital, Oslo, Norway

12 Department of Cancer Prevention and Department of Oncological Gastroenterology, The Maria SklodowskaCurie National Research Institute of Oncology, Warsaw, Poland

13 Department of Gastroenterology, University and Polytechnic La Fe Hospital/IIS La Fe, Valencia. Spain
14 Department of Gastroenterology and Hepatology, Hospital Universitario Ramón y Cajal, Universidad de Alcalá, Ramón y Cajal Health Research Institute (IRYCIS), Madrid, Spain

15 Department of Gastroenterology and Hepatology, Radboud University Medical Center, Nijmegen, The Netherlands

16 Division of Gastroenterology, Ulster Hospital, Dundonald, Belfast, Northern Ireland

17 Hepatogastroenterology Unit, Second Department of Internal Medicine - Propaedeutic, Medical School, National and Kapodistrian University of Athens, Attikon University General Hospital, Athens, Greece

18 Digestive Endoscopy Unit, Fondazione IRCCS-Istituto Nazionale Tumori, Milan, Italy

19 Department of Gastroenterology and Hepatology, Colentina Clinical Hospital, Bucharest, Romania

20 Carol Davila University of Medicine and Pharmacy, Bucharest, Romania

21 Department of Gastroenterology, University College London Hospitals, London, United Kingdom

22 Amsterdam UMC location AMC, Amsterdam, The Netherlands

23 Department of Pneumonology, Inselspital, University Hospital, Bern, Switzerland

24 General Hospital Bjelovar, Bjelovar, Croatia

25 University Medical Centre, Ljubljana, Slovenia

26 Tallinn Healthcare College, Tallinn, Estonia

27 Hvidovre Hospital, Copenhagen, Denmark

28 Porto Comprehensive Cancer Center (Porto.CCC) and RISE@CI-IPOP (Health Research Network), Porto, Portugal

published online 21.12 .2021

\footnotetext{
* Co-first authors
} 


\author{
Bibliography \\ Endoscopy 2022; 54: 211-216 \\ DOI 10.1055/a-1700-4897 \\ ISSN 0013-726X \\ (C) 2021. European Society of Gastrointestinal Endoscopy \\ All rights reserved. \\ This article is published by Thieme. \\ Georg Thieme Verlag KG, Rüdigerstraße 14, \\ 70469 Stuttgart, Germany
}

Corresponding author

Helmut Messman, MD, III. Medizinischen Klinik, Klinikum

Augsburg, Stenglinstrasse 2, 86156 Augsburg, Germany

Fax: +49-821-4003331

helmut.messmann@klinikum-augsburg.de

$\begin{array}{ll}\text { ABBREVIATIONS } \\ \text { CDC } & \text { Centers for Disease Control and Prevention } \\ \text { ECDC } & \begin{array}{l}\text { European Centre for Disease Prevention } \\ \text { and Control }\end{array} \\ \text { ESGE } & \begin{array}{l}\text { European Society of Gastrointestinal } \\ \text { Endoscopy }\end{array} \\ \text { ESGENA } & \text { European Society of Gastroenterology and } \\ & \text { Endoscopy Nurses and Associates } \\ \text { FFP } & \text { filtering facepiece } \\ \text { HCP } & \text { healthcare professional } \\ \text { INAAT } & \text { isothermal nucleic acid amplification } \\ \text { IDSA } & \begin{array}{l}\text { Infectious Diseases Society of America } \\ \text { iPC }\end{array} \\ \text { infection prevention and control } \\ \text { PPE } & \text { polymerase chain reaction } \\ \text { SARS-CoV-2 } & \text { severe acute respiratory syndrome corona- } \\ & \text { virus } 2 \\ \text { WHO } & \text { World Health Organization }\end{array}$

\section{Introduction}

The ongoing COVID-19 pandemic has entered a new phase following the introduction and availability of highly effective vaccination therapies that have modified the epidemiology of severe disease [1-5]. Conversely, viral variants (e.g. the Delta variant) with increased transmissibility have developed and become dominant drivers of the pandemic in Europe and throughout the world. This has led to uncertainty regarding infection prevention, viral control strategies, and vaccination regimens [6]. In Europe, as of October 2021, vaccination rollout, with complete double-dose immunization status, has reached $73.5 \%$ of the population, although with a high intercountry variability (ranging from $25 \%$ to $95 \%$ ) [7]. In some countries, the administration of a third ("booster") dose has been initiated for individuals considered at high risk of negative outcomes from COVID-19 [8, 9]. It must also be noted that currently, COVID-19 vaccination rollout is highly imbalanced between high- and low-income countries, with vaccinated population percentages in the latter being as low as $1 \%$ [10]. This has prompted a flow of vaccines into these areas of the world, where strategies for endoscopy resumption and procedure scheduling should be adapted to local epidemiology and regional risk stratifications. For such affected regions of the world, please refer to World Health Organization (WHO) guidelines and guidance documents from the European Society of Gastrointestinal Endoscopy and the European Society of Gastroenterology and Endoscopy Nurses and Associates (ESGE-ESGENA) and their adaptations to low-resources settings [11-15].

Despite the worldwide introduction of COVID-19 vaccinations, gastrointestinal ( $\mathrm{Gl}$ ) endoscopy continues to entail a significant risk of infection and morbidity from COVID-19, for both health care professionals (HCPs) and patients. Infection prevention and control (IPC) has been shown to be dramatically effective in assuring the safety of both patients and HCPs $[16,17]$. ESGE (www.esge.com) and ESGENA (www.esgena.org) continue to join forces in this updated Position Statement, to provide ongoing guidance during the pandemic to help assure the highest level of GI endoscopy care and protection against COVID-19 for both our patients and endoscopy unit personnel. This guidance is based upon the best available evidence in the current context of COVID-19 vaccines and SARS-CoV-2 viral variants.

\section{Methods}

As in our previous ESGE-ESGENA Position Statements on GI endoscopy and COVID-19 [14, 15], a PubMed/MEDLINE search was performed once again, using "severe acute respiratory distress syndrome coronavirus 2," "COVID-19," "endoscopy, digestive system endoscopy," "gastrointestinal endoscopic examination, therapy," "vaccination", and "viral variants" as MeSH terms, between February 1, 2020 and October 15, 2021 , to identify relevant publications that could inform this updated Position Statement. When applicable, recommendations by international medical bodies, such as WHO, the European Centre for Disease Prevention and Control (ECDC), and the US Centers for Disease Control and Prevention (CDC), have also been considered and adapted. 


\section{Recommendations}

\section{RECOMMENDATION}

1 ESGE-ESGENA recommend that infection prevention and control (IPC) regimens recommended in our previous COVID-19 Position Statements remain in place. This applies to patient triage, IPC training, social distancing/ mask wearing, patient isolation/separation, role of telemedicine, personal hygiene/disinfection, and appropriate use of personal protective equipment (PPE).

\section{RECOMMENDATION}

2 ESGE-ESGENA recommend that where there are shortages of filtering facepiece (FFP) or KN95 masks, it is reasonable to use a standard surgical mask when performing endoscopy (upper and/or lower GI endoscopy procedures) in patients who are negative in polymerase chain reaction (PCR) or isothermal nucleic acid amplification (INAAT) testing within 48 hours before their endoscopy examination, or who provide documentation of full COVID-19 vaccination status or recovery from COVID-19 infection within the past 6 months (e.g. the European Union Digital COVID Certificate. Other PPE (e.g., gloves, hair cover, protective eyewear, waterproof gowns, booties/ shoe covers), should continue to be used as recommended in our previous Position Statements [14, 15].

\section{RECOMMENDATION}

3 ESGE-ESGENA recommend that all patients arriving at the $\mathrm{Gl}$ endoscopy unit be required to wear masks and observe social distancing.

Pre-endoscopy screening for COVID-19 symptoms remains central in disease prevention and control. Given the current state of knowledge, WHO advises that all IPC measures for COVID-19 in health facilities be maintained for vaccinated health care workers [18]. In addition, the United States CDC state that HCPs should continue to follow all current IPC recommendations, including those addressing the use of PPE, to protect themselves and others from SARS-CoV-2 infection [19]. However, for vaccinated HCPs working in facilities located in areas with low community transmission and caring for asymptomatic vaccinated patients, a downgrading from FFP-2/KN95 masks to surgical masks can be considered [20].

\section{RECOMMENDATION}

4 ESGE-ESGENA recommend that all patients presenting for $\mathrm{Gl}$ endoscopy be required to provide either:

(a) A negative viral test (PCR or INAAT) performed within 48 hours before their scheduled GI endoscopy; or

(b) Documentation of full COVID-19 vaccination status or recovery from COVID-19 infection within the past 6 months (e.g. European Union Digital COVID Certificate).

\section{RECOMMENDATION}

5 ESGE-ESGENA do not recommend prioritization based on COVID-19 immunity status of patients awaiting $\mathrm{Gl}$ endoscopy, since this does not appear to be ethical.

Notwithstanding the reported high effectiveness of vaccination, recent data suggest a waning antibody response in vaccinated individuals after approximately 6 months [4, 21-24]. This is also reported in individuals after recovery from SARS-CoV-2 infection, with breakthrough COVID-19 infections being reported both in vaccinated individuals and in persons with acquired natural immunity $[25,27]$. In addition, these infections have been shown to be asymptomatic or paucisymptomatic, while remaining capable of transmitting the virus [28,29]. For these reasons, to maximize patient and HCP protection, ESGEESGENA suggest that regardless of vaccination or previous infection status, all individuals presenting for Gl endoscopy should provide proof of a negative viral test with PCR or INAAT performed within 48 hours before their scheduled procedure, or documentation of full COVID-19 vaccination status or recovery from COVID-19 infection within the past 6 months (e.g. the European Union Digital COVID Certificate).

In places where access to viral testing is limited or unavailable, we suggest that asymptomatic patients presenting for $\mathrm{Gl}$ endoscopy with official documentation of full vaccination status or recent recovery from COVID-19 infection should not be obliged to undergo pre-endoscopic viral testing. This is based on evidence that asymptomatic COVID-19 infection is extremely rare in patients scheduled for $\mathrm{Gl}$ endoscopy, ranging from 0 to $1.5 \%$ in prevaccination era published series, but still highly dependent on local epidemiology [30]. In addition, this low value must be considered alongside the high rate of vaccinated HCPs and the continuous use of PPE, which should reduce infection risk even more. All patients without proof of full vaccination or recovery from recent infection must in any case undergo viral testing before endoscopy.

\section{RECOMMENDATION}

6 ESGE-ESGENA recommend that pre-endoscopy viral testing (PCR or INAAT) be performed immediately in all symptomatic patients. Where viral testing is negative, patients may undergo $\mathrm{Gl}$ endoscopy, thus avoiding postponement of procedures. 
ESGE recommends that both patients and HCPs with COVID19 symptoms undergo immediate viral testing with PCR or INAAT. This is based on recommendations from both American and European centers for disease control that all symptomatic patients and HCPs, regardless of vaccination status, should receive a viral test immediately upon symptom onset [19, 30, 31]. This would mean that no symptomatic patient should undergo Gl endoscopy before having a highly accurate negative test (PCR or similar). If a symptomatic patient presents with a reliable, highly sensitive negative viral test, the GI endoscopic procedure should not be postponed.

\section{RECOMMENDATION}

7 ESGE-ESGENA do not recommend the use of serology or rapid antigen testing (including home self-testing kits) for pre-endoscopy patient triage.

The Infectious Diseases Society of America (IDSA) has developed guidelines on serologic testing for the diagnosis of COVID-19. In detail, the IDSA recommends against the use of serological testing to diagnose past SARS-CoV-2 infection, since precise definitions of timing and antibody kinetics are lacking [32]. In addition, serological tests have no role in the diagnosis of asymptomatic infection. The use of antigen testing or of selftesting should not be accepted as adequate screening prior to $\mathrm{Gl}$ endoscopy because of the uncertain quality of specimen collection, performance of the self-testing procedure, and low test sensitivity [33].

\section{RECOMMENDATION}

8 ESGE-ESGENA recommend that all healthcare professionals (HCPs) working in a Gl endoscopy unit be fully vaccinated against COVID-19.

\section{RECOMMENDATION}

9 ESGE-ESGENA recommend a return to full GI endoscopy procedure capacity in those areas with an ongoing vaccination policy, while continuing to adhere to IPC measures.

\section{RECOMMENDATION}

10 ESGE-ESGENA recommend that GI endoscopy units involved in $\mathrm{Gl}$ endoscopy training and research activities resume their endoscopy training programs and research activities, provided all involved individuals are fully immunized with regard to COVID-19 (i. e., vaccinated or recovered).
ESGE-ESGENA strongly recommends that all HCPs working in $\mathrm{Gl}$ endoscopy units receive a complete vaccination regimen. Full vaccination has been shown to substantially reduce severe COVID-19 manifestations, intensive care unit need, and death $[4,34]$. ESGE-ESGENA believe that HCPs should follow their national policies and regulations, including in some European countries where vaccination has now been made mandatory for all HCPs. Whenever possible, HCPs without immunization should have no or only limited patient contact. Moreover, any HCP working in Gl endoscopy who develops COVID-19 symptoms, should not report to work and should immediately have PCR or INAAT viral testing.

\section{RECOMMENDATION}

11 ESGE-ESGENA suggest that for HCPs who have recovered from COVID-19 infection, proof of natural immunity (up to 6 months post-infection) may be considered equivalent to vaccine immunity, provided the HCP can provide documentation of the previous infection (PCR or INAAT test).

\section{RECOMMENDATION}

12 ESGE-ESGENA recommend that patients' fears of contracting COVID-19 infection while visiting a GI endoscopy unit should be properly addressed. This especially includes having in place appropriate vaccination policies for HCPs and protective policies for those patients at high risk of contracting COVID-19 or of having poor outcomes from COVID-19 infection (e.g., unvaccinated elderly individuals, or those with comorbidities, or who are immunocompromised).

\section{RECOMMENDATION}

13 ESGE-ESGENA do not recommend physical separation of patients based on vaccination status since this does not seem to be logistically feasible or ethical, and since vaccination for the general population is currently not mandatory.

Data suggest that most individuals who have recovered from COVID-19, even after mild infections, carry some protection against re-infection from SARS-CoV-2 for at least 1 year [35]. However, post-vaccination studies show waning antibody titers and increased risk of breakthrough infection 6 months after vaccination $[8,23]$. For this reason, it is reasonable to suggest a 6-month post-infection duration of immunity that is equivalent to vaccine immunity for HCPs working in Gl endoscopy units, if proof of infection can be provided. 


\section{RECOMMENDATION}

14 ESGE-ESGENA recommend that during the ongoing COVID-19 pandemic prioritization of GI endoscopy procedures, based upon clinical and/or oncological indications, should be optimized in those areas with limited endoscopic capacity.

We suggest referring to the previous ESGE-ESGENA Position Statements regarding the priority to be given to GI endoscopy procedures according to indication $[14,15]$.

\section{Disclaimer}

ESGE-ESGENA position statements represent a consensus of best practice based on the available evidence at the time of preparation. They may not apply in all situations and should be interpreted in light of specific clinical situations and resource availability. Further controlled clinical studies may be needed to clarify aspects of these statements, and revision may be necessary as new data appear. Clinical considerations may justify a course of action at variance to these statements. ESGE-ESGENA position statements are intended to be an educational device to provide information that may assist endoscopists and GI endoscopy nurses in providing care to patients. They are not rules and should not be construed as establishing a legal standard of care or as encouraging, advocating, requiring, or discouraging any specific treatment.

\section{Competing interests}

M. Dinis-Ribeiro has provided teaching consultancy to Boston Scientific (2019) and consultancy to Medtronic (2020); his department receives an educational grant from Olympus (ongoing) and a research grant from Fujifilm (ongoing); he is Co-Editor-in-Chief of Endoscopy. B. Fehrke has received a lecture fee from Olympus (2021) and a presenter's fee from Ambu (2021). C. Hassan has received research support from Medtronic, Fujifilm, AlfaSigma, and Norgine (all 20202021). M.F. Kaminski has provided consultancy to Olympus (from 2016) and Erbe (from 2021), and lectures for Boston Scientific (from 2016) and Recordati (from 2020). H. Messman, in the past 3 years, has received benefits from the following endoscopy companies: Apollo Endosurgery, Biogen, Boston Scientific, CDx Diagnostic, Cook Medical, CSL Behring, Dr. Falk Pharma, Endo Tools Therapeutics, Erbe, Fujifilm, Hitachi, Janssen-Cilag, Medwork, Norgine, Nutricia, Olympus, Ovesco Endoscopy, Servier Deutschland, and US Endoscopy; he has received grants from Amgen, Bayer, Dr. Falk Pharma, MSD, Novartis, Olympus and Roche; he has received honoraria from Covidien, Dr. Falk Pharma, and Olympus, and consultancy fees from Boston Scientific, CDx Diagnostics, Covidien, Erbe, Lumendi, Norgine, and Olympus; he has received research support from Olympus (ESD-Register) and Satisfai. E. Rodriguez de Santiago has received a speaker's fee from, and engaged in educational activities for, Olympus (2020-2021). P. Siersema has received or is receiving research support from Pentax (2019-2021), The E-Nose Company (2018-2021), Lucid Diagnostics (2021-2022), MicroTech (2019-2022), Magnetiq Eye (2021-2022), and receives research support from and is advising Motus GI (20182022); he is Editor-in-Chief of Endoscopy. G. Antonelli, M. Arvanitakis, U. Beilenhoff, P. Bhandari, R. Bisschops, M. Bretthauer, A. Ebigbo, A. Fuchs, M. Gazic, T. Gjergek, V. Lorenzo-Zuniga, S. Maasen, M. de Pater,
T.C. Tham, K. Triantafyllou, A. Tringali, A. Voiosu, W. Waagenes, and G. Webster have no competing interests to declare.

\section{References}

[1] Baden LR, El Sahly HM, Essink B et al. Efficacy and safety of the mRNA1273 SARS-CoV-2 vaccine. N Engl J Med 2021; 384: 403-416 doi:10.1056/NEJMoa2035389

[2] Polack FP, Thomas S], Kitchin N et al. Safety and efficacy of the BNT162b2 mRNA Covid-19 vaccine. N Engl J Med 2020; 383: 26032615 doi:10.1056/NEJMoa2034577

[3] Voysey M, Costa Clemens SA, Madhi SA et al. Single-dose administration and the influence of the timing of the booster dose on immunogenicity and efficacy of ChAdOx1 nCoV-19 (AZD1222) vaccine: a pooled analysis of four randomised trials. Lancet 2021; 397: 881-891 doi:10.1016/S0140-6736(21)00432-3

[4] Thomas SJ, Moreira ED, Kitchin N et al. Safety and efficacy of the BNT162b2 mRNA Covid-19 vaccine through 6 months. N Engl J Med 2021: doi:10.1056/NEJMoa2110345

[5] Sadoff ], Gray G, Vandebosch A et al. Safety and efficacy of singledose Ad26. COV2.S vaccine against Covid-19. N Engl J Med 2021; 384 : 2187-2201 doi:10.1056/NEJMoa2101544

[6] Lopez Bernal ], Andrews N, Gower C et al. Effectiveness of Covid-19 vaccines against the B.1.617.2 (Delta) variant. N Engl J Med 2021; 385: 585-594 doi:10.1056/NEJMoa2108891

[7] European Centre for Disease Prevention and Control (ECDC). COVID19 Vaccine Tracker [cited 2021 Oct 4]. Available from: https://vaccinetracker.ecdc.europa.eu/public/extensions/COVID-19/vaccinetracker.html\#uptake-tab

[8] Bar-On YM, Goldberg Y, Mandel M et al. Protection of BNT162b2 vaccine booster against Covid-19 in Israel. N Engl J Med 2021; 385: 1393-1400 doi:10.1056/NEJMoa2114255

[9] Krause PR, Fleming TR, Peto R et al. Considerations in boosting COVID-19 vaccine immune responses. Lancet 2021; 398: 1377-1380 doi:10.1016/S0140-6736(21)02046-8

[10] The WHO is right to call a temporary halt to COVID vaccine boosters. Nature 2021; 596: 317 doi:10.1038/d41586-021-02219-w

[11] World Health Organization. Rational use of personal protective equipment for COVID-19 and considerations during severe shortages. https://www.who.int/publications/i/item/rational-use-of-personalprotective-equipment-for-coronavirus-disease-(covid-19)-and-considerations-during-severe-shortages

[12] Ebigbo A, Karstenson JG, Bhat P et al. Impact of the COVID-19 pandemic on gastrointestinal endoscopy in Africa. Endosc Int Open 2020; 8: E1097-E1101

[13] Antonelli G, Karsensten JG, Bhat P et al. Resuming endoscopy during COVID-19 pandemic: ESGE, WEO and WGO Joint Cascade Guideline for Resource Limited Settings. Endosc Int Open 2021; 9: E543-E551 doi:10.1055/a-1400-9135

[14] Gralnek IM, Hassan C, Beilenhoff $U$ et al. ESGE and ESGENA Position Statement on gastrointestinal endoscopy and the COVID-19 pandemic. Endoscopy 2020; 52: 483-490 doi:10.1055/a-1155-6229

[15] Gralnek IM, Hassan C, Beilenhoff $U$ et al. ESGE and ESGENA Position Statement on gastrointestinal endoscopy and COVID-19: An update on guidance during the post-lockdown phase and selected results from a membership survey. Endoscopy 2020; 52: 891-898 doi:10.1055/a-1213-5761

[16] Suzuki T, Hayakawa K, Ainai A et al. Effectiveness of personal protective equipment in preventing severe acute respiratory syndrome coronavirus 2 infection among healthcare workers. J Infect Chemother 2021; 27: 120-122 doi:10.1016/j.jiac.2020.09.006 
[17] Ingram C, Downey V, Roe M et al. COVID-19 prevention and control measures in workplace settings: a rapid review and meta-analysis. Int J Environ Res Public Health 2021; 18: 7847 doi:10.3390/ ijerph 18157847

[18] World Health Organization. Infection prevention and control during health care when novel coronavirus ( $\mathrm{nCoV}$ ) infection is suspected [cited 2020 Apr 3]. Available from: https://www.who.int/publicationsdetail/infection-prevention-and-control-during-health-care-whennovel-coronavirus-(ncov)-infection-is-suspected-20200125

[19] Centers for Disease Control (CDC). Interim infection prevention and control recommendations for healthcare personnel during the coronavirus disease 2019 (COVID-19) pandemic [cited 2020 Apr 4]. Available from: https://www.cdc.gov/coronavirus/2019-ncov/hcp/infection-control-recommendations.html

[20] Bartoszko J], Farooqi MAM, Alhazzani W et al. Medical masks vs N95 respirators for preventing COVID-19 in healthcare workers: A systematic review and meta-analysis of randomized trials. Influenza Other Respir Viruses 2020; 14: 365-373

[21] Naaber P, Tserel L, Kangro K et al. Dynamics of antibody response to BNT162b2 vaccine after six months: a longitudinal prospective study. Lancet Reg Health Eur 2021: doi:10.1016/j.lanepe.2021.100208

[22] Goel RR, Painter MM, Apostolidis SA et al. mRNA vaccination induces durable immune memory to SARS-CoV-2 with continued evolution to variants of concern. bioRxiv 457229 [Preprint] 2021: doi:10.1101/ 2021.08.23.457229

[23] Shrotri M, Navaratnam AMD, Nguyen $V$ et al. Spike-antibody waning after second dose of BNT162b2 or ChAdOx1. Lancet 2021; 398: 385387 doi:10.1016/S0140-6736(21)01642-1

[24] Chemaitelly H, Tang P, Hasan MR et al. Waning of BNT162b2 vaccine protection against SARS-CoV-2 infection in Qatar. N Engl J Med 2021: doi:10.1056/NEJMoa2114114

[25] Centers for Disease Control and Prevention (CDC). Why CDC measures vaccine effectiveness [cited 2020 Sep 4]. Available from: https:// www.cdc.gov/coronavirus/2019-ncov/vaccines/effectiveness/whymeasure-effectiveness/breakthrough-cases.html

[26] Gallais F, Gantner P, Bruel T et al. Evolution of antibody responses up to 13 months after SARS-CoV-2 infection and risk of reinfection. EBioMedicine 2021; 71: 103561 doi:10.1016/j.ebiom.2021.103561
[27] Gazit S, Shlezinger R, Perez G et al. Comparing SARS-CoV-2 natural immunity to vaccine-induced immunity: reinfections versus breakthrough infections. medRxiv 21262415 [Preprint] doi:10.1101/ 2021.08.24.21262415

[28] Antonelli M, Penfold RS, Merino J et al. Risk factors and disease profile of post-vaccination SARS-CoV-2 infection in UK users of the COVID Symptom Study app: a prospective, community-based, nested, casecontrol study. Lancet Infect Dis 2021: doi:10.1016/S1473-3099(21) 00460-6

[29] Bergwerk M, Gonen T, Lustig Y et al. Covid-19 breakthrough infections in vaccinated health care workers. N Engl J Med 2021; 385: 1474-1484 doi:10.1056/NEJMoa2109072

[30] Sultan S, Siddique SM, Singh S et al. AGA Rapid Review and Guideline for SARS-CoV2 testing and endoscopy post-vaccination: $2021 \mathrm{Up}$ date. Gastroenterology 2021; 161: 1011-1029.e11 doi:10.1053/j. gastro.2021.05.039

[31] European Centre for Disease Prevention and Control (ECDC). Infection prevention and control for COVID-19 in healthcare settings - first update. https://www.ecdc.europa.eu/sites/default/files/documents/ COVID-19-infection-prevention-and-control-healthcare-settingsmarch-2020.pdf

[32] Hanson KE, Caliendo AM, Arias CA et al. Infectious Diseases Society of America guidelines on the diagnosis of COVID-19: Serologic testing. Clin Infect Dis 2020: doi:10.1093/cid/ciaa1343

[33] Dinnes J, Deeks J], Adriano A et al. Rapid, point-of-care antigen and molecular-based tests for diagnosis of SARS-CoV-2 infection. Cochrane Database Syst Rev 2020; 8: CD013705 doi:10.1002/ 14651858.CD013705

[34] McDade TW, Demonbreun AR, Sancilio A et al. Durability of antibody response to vaccination and surrogate neutralization of emerging variants based on SARS-CoV-2 exposure history. Sci Rep 2021; 11: 17325 doi:10.1038/s41598-021-96879-3

[35] Wang Z, Muecksch F, Schaefer-Babajew D et al. Naturally enhanced neutralizing breadth against SARS-CoV-2 one year after infection. Nature 2021; 595: 426-431 doi:10.1038/s41586-021-03696-9 